Artículos 

Acta Poetica $33 \cdot 2$

JULIO-DICIEMBRE

$2012(17-29)$

\title{
Saber, conocer, contemplar: India en la historia del pensamiento europeo
}

\author{
Xicoténcatl Martínez Ruiz
}

La tradición intelectual de India ha representado un rol de interlocutor no siempre reconocido en la historia europea de las ideas. Para el pensamiento europeo la dificultad ha radicado en no considerarla como una tradición de pensamiento sistemático basada en un corpus literario con identidad propia y no-europea. Uno de los méritos de la filosofía de Schopenhauer fue considerar la tradición intelectual de India, como parte integral de la historia universal del pensamiento. El propósito aquí es explorar este paralelo entre filosofía de India y filosofía occidental, con la intención de repensar India en la historia universal de las ideas. La tarea específica de este artículo es ofrecer un esbozo de cómo el pensamiento del sur de Asia provee lucidez a problemáticas contemporáneas; esta tarea se desarrolla a partir del trabajo de dos pensadores, a saber: de Arthur Schopenhauer (s. XIX) y Rabindranath Tagore (s. Xx). Este análisis toma como punto de partida las siguientes preguntas. ¿Cómo habrán de entenderse estas coyunturas, encuentros e interpretaciones donde el pensamiento indio fue leído e interpretado por pensadores europeos?, ¿acaso podemos hablar de conjunciones que relacionan ambas tradiciones, la europea y la india?, ¿podemos hablar de un método comparativo que guíe tal ejercicio?

Palabras clave: India y Europa, Schopenhauer, Tagore, filosofía de la educación, estudios comparativos.

The intellectual tradition of India not always has been taken into account as a full recognized speaker in the European history of ideas. Especially for the European thought, the problem is premised by the common idea which considers Indian thought as non-systematic and without a textual corpus characterized by non-European identity. One of Schopenhauer's merits was to think about the Indian intellectual tradition as integral piece of the universal history 
of thought. The purpose of this paper is to explore this parallel between Indian Philosophy and Western Philosophy by the key contention to rethink India into the universal history of ideas. To do so the task is focused on suggestions to contemporary problems by taking as a point of departure the work of two thinkers: Arthur Schopenhauer (19th century) and Rabindranath Tagore (20th century). To start with the analysis the following questions must be addressed. How the encounters and interpretations of Indian thought made by European thinkers should be understood? Can we talk about conjunctions relating both traditions, Europe and India? Can we locate a comparative method as a guide of this comparative exercise?

Keywords: India and Europe, Schopenhauer, Tagore, Philosophy of Education, comparative studies.

Fecha de entrega: 6 de diciembre de 2011

Fecha de aceptación: 1 abril de 2012 
Xicoténcatl Martínez Ruiz

Centro de Estudios de Asia y África, El Colegio de México

Instituto Politécnico Nacional, México

\section{Saber, conocer, contemplar: India en la historia del pensamiento europeo}

\section{Introducción}

La idea original de este artículo es sencilla, pero a la vez le antecede una compleja red de esfuerzos comparativos entre India y Europa. La idea sencilla está basada en la tesis de Bimal Matilal, esto es, haber notado: "un paralelo relevante entre la filosofía clásica de India y la filosofía occidental contemporánea, en el cual el caso de la primera puede ofrecer lucidez a la problemática de la segunda" (Ram-Prasad, "A Comparative Treatment", 339). Por otra parte, en la base de una compleja red de comparaciones está la siguiente premisa. La construcción de una "idea europea de India" ha determinado el estigma de la tradición intelectual del sur de Asia como un interlocutor no siempre reconocido, un interlocutor sin enunciados válidos para el proceso argumentativo, envuelto en un estigma de religión y ausencia de objetividad. Esta idea tiene que reconsiderarse en nuestros días. El propósito aquí es explorar este paralelo entre la filosofía de India y la filosofía occidental, con la intención de repensar India en la historia universal de las ideas. La tarea de ofrecer cierta lucidez a problemáticas contemporáneas desde la tradición del pensamiento indio, se construye desde el trabajo de dos pensadores, a saber: de Arthur Schopenhauer (s. XIX) 
y Rabindranath Tagore (s. xx). Enumero algunas precisiones metodológicas antes de continuar. Hablar de esta exploración ya conlleva un orden basado en las siguientes ideas:

a) No partimos de la idea común en el siglo diecinueve de pensar a India fuera de la historia del pensamiento (Halbfass, India and Europe, 2), ni pretendemos responder al debate tradicional en torno a si las escuelas de pensamiento de India son filosofía o no, el debate lleva siglos y no es conclusivo.

b) Partimos de nuestro tiempo, y es en el debate contemporáneo donde ubicamos problemáticas susceptibles de ser leídas desde tradiciones paralelas, en este caso la filosofía de India, ofreciendo lucidez a tales problemáticas y sin menoscabo de una o de otra.

c) Posicionamos este enfoque de estudio más allá de la discusión acerca de cómo la tradición de India pudo haber influido doctrinas presocráticas. A falta de evidencia concreta para tal hipótesis, exceptuando algunos casos, aproximarnos a este tema nuevamente nos regresa a la construcción de castillos de arena.

Tomando las tres ideas previas como punto de partida, el enfoque de estudio, propuesto aquí, está en cómo ubicar problemáticas comunes a nuestro tiempo y a la diversidad cultural e intelectual en la que vivimos $\mathrm{y}$, en especial, cómo explorarlas mediante otros sistemas de pensamiento, estructuras, categorías, y en este caso desde la tradición intelectual de India. Lo último con el fin de ofrecer otras formas de entendimiento integral de la realidad; esto supone un rigor en el análisis de los textos en lengua sánscrita.

La estructura del artículo es la siguiente. La primera parte presenta un contexto introductorio con el propósito de repensar desde nuestro tiempo el lugar de India en la historia europea de las ideas. La segunda presenta el caso de Schopenhauer y algunas de las tesis del sur de Asia interpretadas por él de manera inclusiva hacia una historia universal de las ideas. El trabajo de Tagore nos ocupará en la tercera parte en la que se explora de nuevo la tesis central y la propuesta de un método de estudio. 


\section{Releyendo una historia de viajes y desencuentros}

¿Cómo se llegó a esta idea europea de India? ¿Acaso la exclusión sistemática del pensamiento indio de la historia de la filosofía, tal y como fue postulada por Hegel en el siglo XIX, se debió a la consideración de India como un interlocutor lejano al espíritu científico y por ello ausente de objetividad? Halbfass explica:

Ciertamente, Hegel nos ofrece el ejemplo de una discusión comprensiva y seria acerca del pensamiento indio. Aun así su segregación histórica de la filosofía del campo de la religión, su devaluación de cualquier forma de nostalgia por la unidad perdida, y su convicción de que Europa, debido a su despliegue real de la filosofía como disciplina comprometida al espíritu del pensamiento científico y libre, ha trascendido esencialmente a Oriente y de esta manera ha contribuido al uso restrictivo del concepto de filosofía y a la auto-determinación de este concepto en la historiografía de la filosofía (India and Europe, 146). ${ }^{1}$

La cita anterior condensa una de las discusiones clásicas para abordar el tema India y Europa, la reflexión estándar se centraría en la siguiente cuestión: ¿por qué la filosofía europea ha tenido dificultad en considerar el pensamiento del sur de Asia como una tradición de pensamiento sistemático, basada en un corpus literario con identidad propia y no-europea? Si tejemos un recuento de momentos centrales tenemos los siguientes. La posibilidad de un diálogo filosófico con India tiene un hecho histórico central con la presencia de Alejandro Magno en el Valle del Indo. Si tal diálogo inició antes no hay ciertamente evidencia para documentarlo, pero si varias conjeturas. Con base en la información que proviene de este periodo tenemos un esbozo de lo que significó para la perspectiva heleno centrista "ver" y "conocer" otro escenario cultural, conceptual, y lingüístico. La información de este encuentro quedó plasmada, entre otras formas, en una conjunción plástica heleno-budista llamada Gandhara, así como los recuentos históricos helenos que nos han llegado en fragmentos como lo es Indica de Megástenes. Pero ¿qué significó la presencia griega para los habitantes del norte del subconti-

${ }^{1}$ La traducción de este y otros textos corresponden al autor [nota del editor]. 
nente? ¿Por qué la falta de relatos frente a la presencia de Alejandro en fuentes brahmánicas de la época? Los fragmentos que nos han llegado de Indica, la obra de Megástenes, dan pinceladas de una estructura (helena) que decodifica a otra (la sociedad brahmánica y el sistema de varnas). Dicha obra de Megástenes es el primer registro que nos ha llegado al respecto; la interpretación de la estructura social, así como los atisbos del sistema de varnas, son claves para entender su hermenéutica; además, para él la cúspide de la estructura social brahmánica está constituida por los filósofos (gimnosofistas), es decir, los brahmanes. Previo a los registros que tenemos de él, resulta difícil documentar influencias, encuentros e intercambios específicos de teorías entre India y Occidente. Sin embargo, Diogenes Laercio puso a discusión el tema de los orígenes de la filosofía, mediante la hipótesis de una posible influencia asiática en el pensamiento griego, esto en su obra The Lives and Characters of Philosophers, que ya desde la traducción al latín de 1431 impactó la relectura de los clásicos resultando en un prolongado silencio europeo hacia el pensamiento asiático. El trabajo de Diogenes Laercio suscitó conjeturas acerca del papel de los sistemas indios de pensamiento para ciertas doctrinas griegas. Tal es el caso del mismo Pitágoras y su concepción del alma que además de la influencia egipcia es fascinantemente cercana a la doctrina del saimsāra. Sin embargo, no hay una definición clara de influencias contundentes.

En el siglo XIX el tema de un origen único de la filosofía y un desarrollo delimitado únicamente a la hélade griega fue una perspectiva que cerró la posibilidad de ubicar la actividad filosófica como ejercicio sistemático de pensamiento floreciente en otras culturas. La exclusión de las tradiciones asiáticas del pensamiento tuvo una premisa básica, a saber, la estructura del pensamiento asiático representa otra vía no necesariamente alineada con los métodos de estudio de la realidad reconocidos en el siglo XIX. Sin embargo, hoy en día algunas de las formas de estudio de la realidad sostenidas en el siglo XIX están rebasadas. Si esto es así, ¿por qué no habríamos de reconsiderar la pertinencia del pensamiento del sur de Asia desde otro horizonte y en ruta hacia una historia universal de las ideas? Una historia, por cierto, en la que el sur de Asia tendría que repensarse con justo reconocimiento y posicionamiento de esta tradición intelectual. 
Desde entonces hay diversos intentos de repensar la "exclusión" o "inclusión" de Asia en la historia del pensamiento europeo como es el caso de O Hernius (Halbfass, India and Europe, 147, 148), donde vemos ejemplos de breves secciones de "worldly wisdom of the Indians". Por su parte A. Schwegler le llama cosmologías míticas de las tradiciones China e India. El enfoque de A. Schwegler está en que solo la tradición Greco-romana-cristiana es la única tradición que puede ser considerada en una historia de la filosofía (152). Por su parte Saint-Hillaire, en su Dictionnairie des sciences philosophiques (1844), menciona: “en la historia de la filosofía, nada es más novedoso y más importante hoy que el estudio de los sistemas indios" (154).

La investigación más especializada en indología tiene un impulso con Jones, Wilkins, Duperron, Schopenhauer, Schlegel, entre otros, y Nietzsche a su manera (Smith, "Nietzsche's Hinduism"). El siglo XIX es un periodo de debate en torno a la idea de India, su ubicación o exclusión de la historia del pensamiento. Por otra parte, a inicios del siglo Xx tenemos un enfoque de estudio que continúa el interés alemán por la filología sánscrita, un ejemplo es la traducción de fuentes por ejemplo el Dhvanyaloka. Sin embargo, es Hegel y su perspectiva de la India como una tierra maravillosa y al mismo tiempo llena de mitos y vida religiosa, la que impulsa la idea de exclusión de la tradición india de Europa.

\section{Schopenhauer y los fundamentos comparativos}

Uno de los méritos de la filosofía de Schopenhauer fue tomar en cuenta a la tradición intelectual de India como parte integral de la historia universal de las ideas. Schopenhauer no fue el primero en reconsiderar la historia intelectual del subcontinente indio estudiando el brahmanismo y el budismo; sin embargo, su análisis trasciende una aproximación meramente religiosa. Reconoce el estatus de la tradición intelectual de India como un interlocutor de la filosofía europea, lo que se vuelve un fundamento para el estudio comparativo, y lo encontramos en su obra El Mundo como Voluntad y Representación (1818). Esta aproximación fue construida con premisas que antecedieron a Schopenhauer y en gran medida hicieron eco no solo en él, sino en la literatura y filosofía ale- 
manas del siglo XIX. ¿Cómo se entendió el pensamiento indio desde la lectura de pensadores europeos?, ¿acaso podemos hablar de conjunciones que relacionan ambas tradiciones, la europea y la india?, ¿podemos hablar de un método comparativo que guíe tal ejercicio?

A la primera pregunta puede decirse que la interpretación hecha por Schopenhauer a los dilemas éticos del sujeto, dilemas que la filosofía europea había debatido por siglos, fueron releídos desde la literatura sánscrita que proveía una respuesta no judeo-cristiana a la acción y destino humanos. La interpretación de los pensadores europeos se enfocó a la Bhagavad Gìtā, traducida del sánscrito al inglés por Charles Wilkins en 1785. Posteriormente en 1823 A. von Schlegel la traduce al latín con comentarios; esta es la versión que Schopenhauer consultó. Por otra parte, Schopenhauer tuvo preferencia por la versión en latín de las Upanișad-s que Anquetil Duperron dio a conocer en 1801 y 1802. Duperron tradujo cincuenta Upanișad-s al latín de una traducción persa auspiciada por el príncipe Dārā Shukoh en 1657. También se conoció la traducción al inglés de Henry Colebrooke en 1805. De la traducción persa, Rixner Thaddaus presenta en 1808 la versión al alemán de una selección de Upanișad-s.

En la Bhagavad Gìtā, la solución del conflicto interior generado por el dilema moral del sujeto es el conocimiento (jñāna). El conocimiento no es información sino entendimiento de la naturaleza más íntima de la realidad y llevado a la acción. La acción con conocimiento es acción libre de ignorancia, guiada por el entendimiento de un único principio metafísico como causa de la existencia. Schopenhauer consideraba en este sentido que la comprensión de lo imperecedero es la guía del actuar humano. El fundamento de la acción es revelado por Kụșṇa al guerrero Arjuna en la Bhagavad Gìtä; tal fundamento es el conocimiento del ser (jñāna). Schopenhauer lo expresa de esta manera:

Por lo tanto, la multiplicidad y la divisibilidad pertenecen solo al mero fenómeno, y es una y la misma esencia la que se presenta en todo lo viviente; y así aquella concepción que supera la diferencia entre el yo y el no-yo no es la equivocada [...]; ella sería la base metafísica de la ética y consistiría en que un individuo reconoce inmediatamente en el otro a sí mismo, su propio ser verdadero (Los dos problemas fundamentales de la ética, 293-294). 
Para Schopenhauer, la Bhagavad Gìtā tiene un lugar central en la argumentación de una ética no judeo-cristiana, donde no hay una determinación heterónoma como es la idea de pecado original. Este proyecto lo leemos en El Mundo como Voluntad y Representación (de aquí en adelante $M V R$ ). La inclusión de la Bhagavad Gìtā en el pensamiento de Schopenhauer sostiene que la ética descansa en un fundamento metafísico, en el mismo principio ontológico que es fundamento de la existencia $(M V R, 160)$. En otro pasaje él entiende que la voluntad es una unidad metafísica, el fundamento de la ética:

Antes bien, todo lo que puedo hacer por mi parte, [...] es documentar con una cita cómo aquella metafísica de la ética era ya hace milenios la visión fundamental de la sabiduría hindú, a la que yo me remito con Copérnico al sistema cosmológico de los pitagóricos que Aristóteles y Tolomeo desplazaron (Sobre el fundamento de la moral, en Los fundamentos, 297).

En el párrafo sesenta y tres del $M V R$ hay otro pasaje relevante a este ensayo. Schopenhauer escribe: "Al contrario, la sabiduría hindú invade Europa y está llamada a operar una radical transformación en nuestras opiniones y en nuestros pensamientos" (72). El diálogo entre Schopenhauer y el pensamiento asiático muestra un reconocimiento y apertura a otra forma de entender la realidad, este es un mérito de su proyecto filosófico e indicador de un fundamento para el estudio comparativo entre diversas tradiciones intelectuales. El reconocimiento a la historia de las ideas del sur de Asia tiene que ser replanteado desde nuestro tiempo, es decir, sin prejuicio y tomando como ventaja las múltiples fuentes a las que ahora podemos acceder y que Schopenhauer no conoció. Nuestro siglo XXI tiene una tarea concreta en desmitificar o bien considerar la "transformación de nuestras opiniones y nuestros pensamientos" (72).

Para Schopenhauer no existe algo externo que mejore esencialmente y de manera radical nuestra condición humana, ni un sistema político ni una reforma jurídica; la transformación es interna, ocurre en el ser humano pero no desde el exterior sino en lo más profundo de nuestra humanidad. Repensar la actualidad de este diálogo iniciado por Schopenhauer con el pensamiento del sur de Asia significa volver a mirar una 
historia de las ideas de una manera más integral. El análisis que hace Schopenhauer de los sistemas de pensamiento indio coincide con su idea de un camino de salvación, de redención de la miseria, liberación de la condición de sufrimiento que él encuentra de manera lúcida en el budismo; tal aspiración filosófica conduce a una comprensión integral de la realidad.

\section{Tagore: imaginación y pensamiento}

Uno de los debates en educación con mayor vigencia en nuestros días es el papel de la imaginación creativa y el pensamiento crítico en las reformas educativas a gran escala. Un tema que fue pensado y aplicado concretamente por Rabindranath Tagore en el siglo xx. La filosofía de la educación de Tagore es el fundamento teórico del pensamiento educativo de Martha Nussbaum, quien ha considerado la vigencia de las ideas pedagógicas de Tagore en la crisis educativa que enfrentamos en nuestros días, con especial pertinencia para México. En su defensa del papel de las humanidades en la educación, Nussbaum regresa a Tagore y desde ahí sostiene que el ejercicio crítico del pensamiento y la formación humanística es esencial para la democracia. Este ejercicio tiene un rol que ha sido subestimado por las recientes políticas gubernamentales hacia la educación. Una acción que vulnera la posibilidad del ejercicio democrático (Nussbaum, "Education and Democratic Citinzenship"). La filosofía de la educación de Tagore provee sugerencias para repensar dicha problemática educativa actual; problemática generada por las reformas educativas a gran escala diseñadas sin fomento al pensamiento crítico y minimizando los contenidos humanísticos. Rabindranath Tagore fue un defensor de las humanidades y el arte para fomentar la educación crítica, humanista y creativa.

Tagore, citado por Martha Nussbaum, presenta una de las razones para considerar la pertinencia del pensamiento indio: "La historia ha llegado a un punto en el que el hombre moral, el hombre íntegro, está cediendo cada vez más espacio, casi sin saberlo [...] al hombre comercial, el hombre limitado a un solo fin" (Nussbaum, Sin fines de lucro, 7). Hoy podemos hablar del modelo educativo de Tagore que se con- 
cretó mediante un programa de fomento al pensamiento crítico y a la imaginación creativa. Tagore construyó un modelo educativo en el que las formas de expresión y asimilación del conocimiento fueron la base de una idea de ser humano. Para el nobel bengalí el "aprendizaje" es la apropiación de la realidad y la vida, ejemplificado en una pedagogía que fomenta las actividades de expresión corporal para comunicar lo aprendido.

Otro ejemplo es su concepción de educador, ¿quién y cómo se es un guía, un educador? Esta concepción encuentra fundamento en las Upanișad-s, textos que contienen reflexiones filosóficas y debates acerca de la acción y el destino humanos. En algunas Upanișad-s la centralidad de la enseñanza transmitida en diálogos y reflexiones se acentúa mediante la manera en que impacta al estudiante, las formas de aprendizaje son diversas; sin embargo, más relevante se vuelve la figura de quien transmite la enseñanza (véase Radhakrishnan, The Principal Upanișads, 502). Este vehículo transmisor, en la tradición pos-védica, está en la figura del Maestro que para Tagore es un modelo de educador. La concepción de Maestro en las Upaniṣad-s solo lo es en tanto él, el Maestro, encarna lo que enseña, quien enseña es el que ha transitado, por tanto, el camino para estar en posesión del conocimiento. En su acción como educador, el Maestro aludido en las Upanișad-s utiliza diversos métodos, ejemplos, metáforas, acciones, incluso el silencio tiene su función pedagógica. Las diversas historias de estos Maestros impactaron a Tagore y en especial su configuración de lo que caracteriza a un pedagogo. Estos métodos que se describen en las Upanișad-s y que pueden ubicarse entre los siglos VIII y VII a.e.c., hoy tienen vigencia en ámbitos educativos prioritarios como es el de la habilidad lectora. Esto ha sido expuesto previamente como otro ejemplo de la vigencia del pensamiento indio para el tratamiento de problemáticas actuales; el argumento central se resume enseguida. El tratamiento secular de técnicas de atención y concentración, propias de la tradición de India, muestra en nuestro tiempo vías para la solución de uno de los problemas que enfrenta el sistema educativo mexicano, esto es, la disminución de la capacidad lectora. Luego, el tratamiento secular de elementos derivados de prácticas de la tradición de India, en particular la atención dirigida y la concentración sostenida (en sánscrito dhāraṇa a), y su integración para el desarrollo de 
la habilidad lectora, es una forma de sugerir aproximaciones paralelas a problemáticas actuales (Martínez Ruiz, "Dhāraṇā: atención dirigida y concentración sostenida", 130).

La pertinencia de una aproximación secular a la tradición filosófica de India es un punto de partida central para Tagore, incluso la concepción de Maestro y su función de educador quedó plasmada en pasajes memorables como este, tomado de una conferencia que Tagore leyó en 1921 en el Instituto Jean Jacques Rousseau de Ginebra: "No se puede enseñar más que aquello que se ama; vale más callarse cuando no gustamos de lo que estamos enseñando. Así pues, no debemos enseñar más que aquello que guarda para nosotros un cierto misterio". Bimal Matilal entendió que el proyecto de Tagore suscitó la reflexión en torno a las ideas del siglo XIX, repensando la idea de una sociedad más universal, y diremos que en gran medida fomentada por un modelo educativo integral y humanista. Dicho autor explica: "Esta es una especie de universalismo - el ejemplo que Tagore proyectó mediante sus poemas y otros escritos. Por ello en el mundo plural de hoy, con diversas razas, naciones, sistemas políticos y sociales, el trabajo de Tagore tiene una relevancia especial" (apud O'Connell, "Tagore and Education”, 71).

\section{A manera de conclusión}

En The Character of Logic in India, Bimal Matilal condensa uno de los propósitos que ha guiado este breve ensayo, y que a manera de conclusión puede resumirse en estas líneas. Al ser estudiado mediante estándares teóricos, el pensamiento indio reivindica sus dimensiones verdaderamente filosóficas en contraste a las perspectivas de los primeros historiadores de la filosofía. Matilal no postuló la idea de que el pensamiento filosófico indio era superior al occidental, tal hubiera sido un error en el otro extremo; por el contrario, Matilal enfocó el análisis comparativo en una apertura a la consideración de un pensamiento sistemático capaz de proveer sugerencias vigentes a la problemática filosófica contemporánea. 


\section{REFERENCIAS}

Halbfass, Wilhelm, India and Europe: An Essay in Philosophical Understanding, Delhi, Motilal Banarsidass, 1990.

Halbfass, Wilhelm, On Being and what there is. Classical Vaiśeșika and the History of Indian Ontology, Albany, State University of New York Press, 1992.

MarTínez Ruiz, Xicoténcatl, "Dhāraṇā: atención dirigida y concentración sostenida. Un análisis del rezago de lectura en adolescentes mexicanos”, en Epistemología y formación: horizontes de investigación, Guanajuato, Departamento de Educación, Universidad de Guanajuato, 2011.

Matilal, Bimal Krishna, The Character of Logic in India, Jonardon Ganeri y Heeraman Tiwari (ed.), Albany, State University of New York Press, 1998.

Nussbaum, Martha Craven, Sin fines de lucro. Por qué la democracia necesita de las humanidades, Buenos Aires, Katz Editores, 2010.

Nussbaum, Martha Craven, "Education and Democratic Citinzenship: Capabilities and Quality Education”, Journal of Human Development, 7, 3, 2006, 385-395.

O’Connell, Kathleen, “Tagore and Education: Creativity, Mutuality and Survival", Asiatic, 4, 1, 2010, 65-76.

Radhakrishnan, S., The Principal Upanisads, New Delhi, Harper Collins Publishers India, 1999.

Ram-Prasad, Chakravarthi. "A Comparative Treatment of the Paradox of Confirmation", Journal of Indian Philosophy, 30, 2002, 339-358.

Saint-Hillaire, B. "Indieus (Philosophies)", en Dictionnaire des sciences philosophiques, Frank, A. (ed.), vol. III, deuxième edition, Paris, Librairie Hachette, 1875, pp. 781-791.

Smith, David, "Nietzsche's Hinduism, Nietzsche's India: Another Look", Journal of Nietzsche Studies, 28, 2004, 37-56.

Schopenhauer, Arthur, El Mundo como Voluntad y Representación, trad. de Eduardo Ovejero y Mauri, Buenos Aires, Aguilar, 1960.

Schopenhauer, Arthur, Los dos problemas fundamentales de la ética, trad. Pilar López de Santa Ana, Madrid, Siglo XXI, 1993.

TAGORE, Rabindranath, Conferencia en el Instituto Juan Jacobo Rousseau de Ginebra, 1921, editada por Pierre Bovet, publicada en la revista L'Educateur, 11 de junio de 1921 . 
